This is the final accepted manuscript of:

A novel bioluminescent NanoLuc yeast-estrogen screen biosensor (nanoYES) with a compact wireless camera for effect-based detection of endocrine-disrupting chemicals.

Cevenini Luca; Lopreside Antonia; Calabretta Maria Maddalena; D’Elia Marcello; Simoni Patrizia; Michelini Elisa; Roda Aldo.

Cite this article as:

Cevenini, L., Lopreside, A., Calabretta, M.M. et al. Anal Bioanal Chem (2018) 410: 1237.

DOI: https://doi.org/10.1007/s00216-017-0661-7

First Online 30 September 2017

Available at: https://link.springer.com/article/10.1007\%2Fs00216-017-0661-7\#enumeration 


\title{
A novel bioluminescent NanoLuc yeast-estrogen screen biosensor (nanoYES) with a compact wireless camera for effect-based detection of endocrine disrupting chemicals
}

\author{
Cevenini Luca ${ }^{l}$, Lopreside Antonia ${ }^{1}$, Calabretta Maria Maddalena ${ }^{l}, D^{\prime}$ Elia Marcello $^{2}$, Simoni \\ Patrizia $^{3}$, Michelini Elisa ${ }^{1,4,5}$, Roda Aldo ${ }^{1,4}$ \\ ${ }^{1}$ Department of Chemistry “G. Ciamician”, Alma Mater Studiorum, University of Bologna, \\ Bologna, Italy, \\ ${ }^{2}$ Gabinetto Regionale di Polizia Scientifica per l'Emilia Romagna, Via Volto Santo 3, 40123 \\ Bologna, Italy \\ ${ }^{3}$ Department of Medical and Surgical Sciences, Alma Mater Studiorum, University of Bologna, Via \\ Massarenti 9, 40138 Bologna, Italy \\ ${ }^{4}$ INBB, Istituto Nazionale di Biostrutture e Biosistemi, Viale delle Medaglie d'Oro 305, 00136, \\ Rome, Italy \\ ${ }^{5}$ Health Sciences and Technologies-Interdepartmental Center for Industrial Research (HST-ICIR), \\ University of Bologna, Bologna, Italy \\ | *Corresponding author s: \\ Prof. Aldo Roda \\ Department of Chemistry “G. Ciamician”, University of Bologna \\ via Selmi 2, 40126 Bologna, Italy \\ Tel/fax +39051343398 \\ E-mail aldo.roda@ unibo.it \\ Dr. Elisa Michelini \\ Department of Chemistry “G. Ciamician”, University of Bologna \\ via Selmi 2, 40126 Bologna, Italy \\ Tel/fax +39051343398 \\ E-mailelisa.michelini8@unibo.it
}




\section{Abstract}

The presence of chemicals with estrogenic activity in surface, groundwater, and drinking water poses serious concerns for potential threats to human health and aquatic life. At present no sensitive portable devices are available for the rapid monitoring of such contamination.

Here we propose a cell-based mobile platform that exploits a newly developed bioluminescent yeast-estrogen screen (nanoYES) and a low-cost compact camera as light detector. S. cerevisiae cells were genetically engineered with a yeast codon-optimized variant of NanoLuc luciferase (yNLucP) under the regulation of human estrogen receptor $\alpha$ activation.

Ready-to-use 3D printed cartridges with immobilized cells were prepared by optimizing a new procedure that enables to produce alginate slices with good reproducibility. A portable device was obtained exploiting a compact camera and wireless connectivity enabling a rapid and quantitative evaluation ( $1 \mathrm{~h}$ incubation at room temperature) of total estrogenic activity in small sample volumes $\left(50 \_\mu \mathrm{L}\right)$ with a LOD of $0.08 \mathrm{nM}$ for $17 \beta$ estradiol. The developed portable analytical platform was applied for the evaluation of water samples spiked with different chemicals known to have estrogen-like activity. Thanks to the high sensitivity of the newly developed yeast biosensor and the possibility to wireless connect the camera with any smartphone model, the developed configuration is more versatile than previously reported smartphone-based devices, and could find application for on-site analysis of endocrine disruptors.

Keywords: bioluminescence, NanoLuc luciferase, endocrine disruptors, effect-based analysis, estrogenic activity, yeast-based biosensor. 


\section{Introduction}

The monitoring of micropollutants in the aquatic environment represents both a key technical and regulatory challenge that has been addressed in the EU Directive 2008/105/EC (the Environmental Quality Standards Directive, EQSD), later amended with the Directive 2013/39/EU under the European WFD [1]. In particular, several environmental contaminants are known to affect endocrine functions resulting in adverse health effects in humans and wildlife. These compounds, falling under the umbrella of endocrine disrupting chemicals (EDCs), interfere at different levels with the endocrine system, e.g., by binding to the receptors of several hormones (e.g. estrogens, androgens and progestogens, corticosteroids, and thyroid hormones). Different unrelated molecules have been classified as EDCs, including synthetic hormones, polycyclic aromatic hydrocarbons (PAHs), polychlorinated biphenyls (PCBs), dioxins, dibenzofurans, and alkylphenols [2]. This high heterogeneity in chemical structure and physicochemical properties poses significant technical issues for the development of analytical methods and for the identification of an harmonized regulatory framework [3-4]. Although there are no legal discharge limits in the environment, some micropollutants have been recently prioritized at EU level according to their suspected health risks and to the current unavailability of adequate monitoring methods [5]. In 2015, the Joint Research Center published a technical report with the first Watch List containing the following substances: diclofenac, 17 $\beta$-estradiol (E2), Estrone (E1), 17 $\alpha$-ethinylestradiol (EE2), oxadiazon, methiocarb, 2,6-ditert-butyl-4-methylphenol, triallate, imidacloprid/ thiacloprid/ thiamethoxam/ clothianidin/ acetamiprid, erythromycin/ clarithromycin/ azithromycin, and 2-ethylhexyl 4-methoxycinnamate.

Of these ten substances, three compounds, i.e. E2, E1, and EE2 share the same mechanism of action, i.e., via activation of estrogen receptor $\alpha(\mathrm{ER} \alpha)$ [6]. The monitoring of these chemicals is challenging and only expensive and sophisticated laboratory equipment (e.g., mass spectrometry) can provide suitable detection limits for their detection. 
An approach complementary to chemical analysis is represented by effect-based analysis, relying on the evaluation of actual biological activity of a sample, measured as the ability to activate receptors or other molecular targets [7-9]. Receptor-mediated effects are generally measured with bioassays or cell-based assays in which cells are re-programmed to express a reporter protein as a consequence of activation of a specific receptor. Cell-based assay have proven highly valuable tools to understand the level of estrogenic contamination in water bodies $[3,10]$ and for eco-toxicological studies [11-12]. In particular, assays based on both human cell lines and yeasts have been developed by engineering living cells with the human estrogen $\alpha$ or $\beta$ receptor, whose activation drives the expression of a reporter protein such as a luciferase or a green fluorescent protein [13-22] $15 \underline{\underline{\ldots}}$. As an alternative to reporter gene technology [23] achieved detection at sub-ppb levels of estradiol and ppm levels of bisphenol A by engineering E. coli cells to express on the surface native estrogen receptors and exploiting impedance. These assays are able to assess the effective biological activity of a sample taking into account mixture effects and even the presence of unidentified and unknown chemicals. Such information is crucial in the analysis of complex samples containing a high number of chemicals, for example to rapidly detect tap water contamination. Other biosensing approaches have been also explored to develop new tools able to measure estrogenic activity in environmental samples; for example $\lceil 24]$ proposed receptor-based optical biosensors that can be reused for up to $\underline{300 \text { sensing cycles. }}$

Amongst cell-based assays for estrogen-like activity, the most applied are ER-CALUX based on human U2-OS osteosarcoma cell line [2516], E-SCREEN based on MCF-7 human breast adenocarcinoma cell line [2617], and the yeast estrogen screen (YES) developed by Routledge and Sumpter [2718]. In particular YES assay is based on a recombinant Saccharomyces cerevisiae yeast strain of the which contains a gene for the expressionexpressing-ofthe human estrogen receptor hER and a reporter plasmid carrying the reporter gene lac-Z encoding the enzyme $\beta$ -

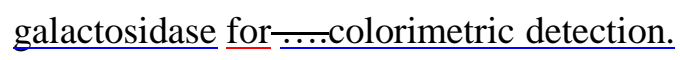


Despite their widespread use in laboratory settings, these assays have been not yet implemented in portable formats. The availability of new methods enabling the on-site analysis would be an extremely helpful tool for routine screening and for providing a rapid alert in case of accidental disasters in order to rapidly undertake proper countermeasures [6].

We previously reported proof-of-principle devices integrating yeast cells for endocrine disruptors, nevertheless the low bioluminescence (BL) emission of the cells required highly sensitive light detectors such as cooled charge-coupled device (CCD) cameras for astrophotography [2819]. We recently reported the obtainment of general toxicity cell biosensors exploiting the smartphoneintegrated camera as detector [29-3020-21]. Yet these biosensors integrated mammalian cell lines, with the well-known limitations related to cell handling and shelf-life. A 3D-printed cartridge was fabricated to integrate cells with a smartphone, simplifying the device itself but limiting its applicability to a single smartphone model. Considering the high number of commercial smartphones and their short lifespan, this represents a serious limitation for real-life applications. Therefore, taking advantage of our experience, we addressed main limitations of previous portable cell biosensors in terms of detectability, universality of the device and shelf-life of the cells. To increase detectability, we developed a new yeast biosensor by exploiting NanoLuc luciferase [3122] as reporter protein, to develop a device of general use we replaced the smartphone with a compact wireless camera that can be connected to any smartphone, and we optimized a novel strategy for obtaining reproducible ready-to-use alginate slices with embedded cells.

\section{Materials and methods}

\section{Chemicals and reagents}

All the reagents required for yeast cell culture maintenance were from Sigma-Aldrich (St. Louis, MO). Synthetic complete (SC) liquid medium was prepared by adding $6.7 \mathrm{~g}$ yeast nitrogen base w/o amino acids, $1.4 \mathrm{~g}$ yeast synthetic drop-out medium supplement, $10 \mathrm{~mL}$ adenine hemisulfate solution to $1 \mathrm{~L}$ of $\mathrm{H}_{2} \mathrm{O}$. The solution was autoclaved and then $40 \mathrm{ml}$ of glucose $50 \%$ w/v solution 
(0.22 $\mu \mathrm{m}$ filter sterilized) was added. SC-ura-trp-leu medium was prepared by supplementing SC medium with L-histidine (2 g/L). SC (-Ura -Trp -Leu -His) medium was supplemented with Lhistidine (0.02 g/L), L-leucine (0.1 g/L), L-tryptophan $(0.02 \mathrm{~g} / \mathrm{L})$ and uracil (0.02 g/L). 17ßestradiol (E2), 17 $\alpha$-ethynylestradiol (EE2), diethylstylbestrol (DES), estrone (E1) and bisphenol A (BPA) were from Sigma-Aldrich. Dialysis tubing cellulose membrane and the kit for plasmid extraction and purification were from Sigma-Aldrich. FastDigest restriction enzymes, FastAP and T4 DNA Ligase required for cloning and YPER (Yeast Protein Extraction Reagent) were from Thermo Fisher Scientific (Waltham, MA, USA). The bioluminescent substrate furimazine was from Promega (Madison, WI, USA). All other chemicals were purchased form Sigma-Aldrich (St. Louis, MO, USA).

Obtainment of NanoLuc estrogen responsive S. cerevisiae strain Yeast expression plasmid pRSII426 and pBEVY-L were form Addgene (Cambridge, Massachusetts, USA). The yeast codon optimized version of the NanoLuc-PEST luciferase (yNLucP) was a kind gift from Prof. C. Andréasson (Stockholm University, Sweden) [32z3]. The sequence encoding the human estrogen receptor was amplified with polymerase chain reaction (PCR) using pSP72hER $\alpha$ as template and cloned into pBEVY-L (Leu2 marker) vector under the control of constitutive ADH1 promoter, using KpnI and EcoRI sites. The generated vector was called pBEVY-L-ER $\alpha$.

The reporter vector was created by cloning, into a pRSII426 plasmid (Ura3 marker), five copies of an ERE response element (-AGGTCAgagTGACCT-) [3324] upstream of a minimal cytochrome C promoter (CYCmin) driving the expression of the yNLucP coding sequence, giving the plasmid pRSII426-ERE-yNLucP. The correctness of sequences and vectors was confirmed by restriction analysis and sequencing.

The yeast $S$. cerevisiae BMA64-1A (MATa, ura 3-52, trp1 $\Delta 2$ leu2-3 112his3-11 ade2-1, can1-100, wild type strain was used as recipient strain [3425] and transformed with plasmids pBEVY-L-ER $\alpha$ 
and pRSII426-ERE-yNLucP using the LiAc/SS-DNA/PEG method [3526]. Colonies harbouring both vectors were selected in SC-ura-leu plates after incubation at $30{ }_{-}^{\circ} \mathrm{C}$ for 4 days. $15 \%$ glycerol stocks of the recombinant strain were prepared and stored at $-80{ }^{\circ} \mathrm{C}$.

\section{Laboratory-based assay procedure and luminescence measurements}

The novel NanoLuc yeast estrogen screen (nanoYES) assay was carried out in a type II laminar flow cabinet to reduce aerosol formation. Before running an assay, a single colony from an agar plate containing the selective medium was used to inoculate $3.0 \mathrm{~mL}$ of $\mathrm{SC}$ medium. This culture was grown overnight at $30{ }^{\circ} \mathrm{C}$ with orbital shaking at $200 \mathrm{rpm}$ in selective $\mathrm{SC}$ medium.

Briefly, a $3 \_\mathrm{mL}$ overnight yeast culture was diluted in fresh SC medium to optical density $\left(\mathrm{OD}_{600}\right)$ of 0.6 and grown for about $4 \mathrm{~h}$ until $\mathrm{OD}_{600}=1$ was reached. Then, $150 \mu \mathrm{L}$ of culture was dispensed in 96-well microplates and incubated at $25{ }^{\circ} \mathrm{C}$ with different concentrations of E2 (from $0.001 \mathrm{nM}$ to $100 \mathrm{nM}$ ) at $1 \%$ ethanol final concentration, for $1 \mathrm{~h}$. Control wells (CTR) were incubated with $1 \%$ ethanol final concentration. BL emission kinetics were recorded using a Varioskan Flash multimode reader (5 minutes with $300 \mathrm{~ms}$ integration time) after addition of $50 \mu \mathrm{L}$ of an optimized BL substrate containing $10 \mu \mathrm{M}$ furimazine diluted in YPER reagent (YPER-Nano). Light emissions were expressed as relative light units (RLU). The detection limit is defined as the E2 concentration that corresponds to the blank signal plus three times the standard deviation. All experiments were performed in triplicate and repeated at least 3 times.

\section{Fabrication of the mobile platform 3D-printed cartridges and GoProHero5 adaptors}

The compact GoPro HERO 5 videocamera (GoPro, Inc, San Mateo, CA, USA) was chosen as light detector. A cartridge of $60 \times \_40 \mathrm{~mm}, 7 \mathrm{~mm}$ high, containing an array of 16 square wells $(5 \mathrm{~mm}$ wide and 5_mm deep each) was created with a desktop 3D printer (Makerbot Replicator 2X) using black and white thermoplastic polymer acrylonitrile butadiene styrene (ABS) (FormFutura, Nijmegen, 
NL) using the dual extrusion option. The GoProHero5 adaptors and dark-box were printed using black ABS. All pieces were printed at $300 \mu$ m layer resolution, $30 \%$ infill.

Preparation of cartridges with immobilized yeast biosensors.

An overnight culture of yeast cells was diluted in $30 \mathrm{~mL}$ of fresh medium to optical density $\left(\mathrm{OD}_{600}\right)$ of 0.6 and grown for about $4 \mathrm{~h}$ until an $\mathrm{OD}_{600}=1$ was reached. The culture was centrifuged and resuspended in $3 \mathrm{~mL}$ SC-ura-leu medium containing $10 \%$ trehalose and $1.5 \%$ sodium alginate.

This mixture was then poured into a dialysis tubing cellulose membrane (avg. flat width $10 \mathrm{~mm}$, molecular weight cut-off $=14 \mathrm{KDa}$ ) and immersed in a $0.2 \mathrm{M} \mathrm{CaCl}_{2}$ solution for $1 \mathrm{~h}$ at room temperature $\left(25^{\circ} \mathrm{C}\right)$ to allow the formation of the gel inside the membrane. Using a 3D printed "microtome-like" device, that has a slot for a surgical blade placed at $2 \mathrm{~mm}$ from the edge, the obtained gel (about $12 \mathrm{~cm}$ length, avg. diameter $5 \mathrm{~mm}$ ) was repeatedly cut in several slices, then placed into the wells of the 3D-printed cartridges. A $50 \mu \mathrm{L}$-volume of SC medium was added to each well and the cartridges were covered with Parafilm $\mathrm{M}^{\circledR}$ and stored at $4{ }^{\circ} \mathrm{C}$ until use.

The stability of the yeast biosensor kept at $4{ }_{-}^{\circ} \mathrm{C}$ was daily tested by incubating the cells in duplicate with $10 \mathrm{nM} \mathrm{E} 2(50 \mu \mathrm{L})$ for $1{ }_{-} \mathrm{h}$ incubation at room temperature; a $50 \mu \mathrm{L}$-volume of YPER-Nano substrate was added to each well and image was acquired with the GoProHero5 in night mode (30 s, ISO 800) equipped with the 3D printed black-box accessory. Images were analysed with ImageJ software and data plotted using GraphPad Prism v.5 (GraphPad Software, Inc. La Jolla, CA). BL emission was normalized with respect to BL signal obtained at day 0 (freshly immobilized cells). All measurements were performed in duplicate and repeated at least three times with different cell cartridges.

\section{Analytical performance of the GoPro-based yeast estrogen screen}

The analytical performance of the developed platform was performed by incubating yeast estrogen biosensors with increasing concentrations (from $0.05 \mathrm{nM}$ to $10 \mathrm{nM}$ ) of E2, selected as model 
estrogenic analyte. Briefly, a cell-cartridge containing immobilized yeast cells stored at $4^{\circ} \mathrm{C}$ was equilibrated at room temperature for $15 \mathrm{~min}$, then a $50 \mu \mathrm{L}$-volume of E2 dilutions $11 \%$ ethanol final concentration) were added in duplicate wells. Control wells were treated incubated with $1 \%$ ethanol final concentration $(50 \mu \mathrm{L})$. ef $1 \% \mathrm{EtOH}$. After $1 \mathrm{~h}$ incubation at room temperature a $50 \mu \mathrm{L}$-volume of YPER-Nano substrate was added to each well, then the cartridge was inserted into the 3D printed black-box accessory and BL emission was acquired with the GoProHero5 in night mode (30 s, ISO 800). Images were quantified with ImageJ software by selecting a square region of interest (ROI) around each well and measuring the BL emission of duplicate wells. E2 dose-response curves were obtained by calculating the fold response with respect to control and plotted using GraphPad Prism. Non-linear regression was performed by fitting the experimental data using a four-parameters sigmoidal curve, then the EC50 value for E2 was calculated as the effective concentration which produces the midpoint y value $(50 \%)$ of the dose-response curve. All measurements were performed in duplicate and repeated three times with different cell cartridges.

\section{Yeast-estrogen cartridge configuration for effect-based analysis of real semples}

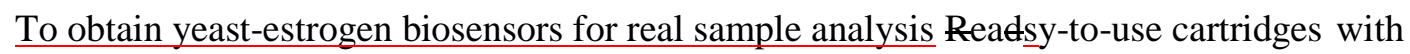
immobilized yeastestrogen biosensorscells were prepared as follows: half of the cartridge was used to test in duplicate the yeast bioreporter response to $0.5,1$ and $5 \mathrm{nM}$ E2 or vehicle only $(-1 \%$ $\mathrm{EtOH})$ as control, while the remaining wells were incubated in duplicate with tap water samples (25 $\mu \mathrm{L})$ spiked with different concentrations of diethylstilbestrol $(0.1$ and $10 \mathrm{nM})$ and bisphenol A (10 $\mathrm{nM})$. Sample wells were also co-incubated with $0.5 \mathrm{nM}$ E2 $(25 \mu \mathrm{L})$. Dilution of estrogenic compounds were prepared to provide a $1 \%$ ethanol final concentration in every well. Cartridges were incubated for $1 \mathrm{~h}$ at room temperature, then a $50 \mu \mathrm{L}$-volume of YPER-Nano substrate was added to each well and BL emission was acquired with the GoProHero5 as described above. Images were quantified with ImageJ software by selecting a square ROI around each well and measuring the mean BL emission of duplicate wells. BL signal were then normalized with 
respect to $0.5 \mathrm{nM}$ E2 (selected as reference and set to 100\%) and plotted using GraphPad Prism. All measurements were performed in duplicate and repeated three times with different cell cartridges.

\section{Results and discussion}

The possibility to use the smartphone camera to detect the BL emission from living whole-cell biosensors has been previously demonstrated by us exploiting genetically engineered mammalian cell lines [29-3020 21]. Despite adequate analytical performance, one of the main limitations of this approach is surely related to the short shelf life of mammalian cells when maintained outside an incubator with controlled temperature and humidity. In addition, considering the short life span of smartphones, mainly due to short battery life and software updates changes, the general applicability of such devices is questionable with the necessity of upgrading and fabricating new devices, with subsequent assay optimization and calibration, for each smartphone model.

In this scenario, a mobile platform based on the use of a compact camera, such as the GoProHero camera, and robust yeast cells as living biosensors could represent a suitable solution to overcome these issues. Indeed, yeast cells are particularly suitable for the development of whole-cell biosensors integrated into a portable mobile platform as they provide the analytical robustness typical of bacterial cells, with the possibility to express functional human receptors and regulatory elements to obtain predictive information about actual biological activity of samples [ $\underline{3627]}$. The GoProHero5, optimized for sport and outdoor activities, represents a robust, waterproof CMOS camera (12_MP, UHD 4K) which can be directly controlled using the built-in touch-screen display or can be connected to any smartphone via dedicated GoPro-App (paired wireless network), making it a very versatile light sensor for the development of portable devices. In addition, the long exposure time (up to $30 \mathrm{~s}$ at ISO 800) makes this camera a powerful choice for low-light imaging applications, including bioluminescence measurements.

Development of a novel yeast-estrogen screen exploiting NanoLuc luciferase (nanoYES) 
The novel yeast-estrogen strain (Fig.1a) was obtained by genetically engineering $S$. cerevisiae cells with two vectors: i) a plasmid for the expression of the human estrogen receptor $\alpha(\mathrm{hER} \alpha)$ under the control of the constitutive ADH1 promoter and ii) a reporter plasmid containing five copies of an ERE response element (-AGGTCAgagTGACCT-) upstream of a minimal cytochrome C promoter (CYCmin) which drives the expression of the yeast codon-optimized NanoLuc luciferase coding sequence (yNLucP). Both vectors contain the $2 \mu$ origin, thus ensuring consistent replication of the two plasmids during cell division and maintaining each plasmid at about 50 copies/cell. Due to the high copy number, the expression of the human estrogen receptor was placed under a weak promoter to avoid strong overexpression that may lead to artefacts in the biosensor response. Indeed, the high copy number of reporter vector allows consistent production of yNLucP reporter enzyme upon induction.

The small size $(19 \mathrm{kDa})$ and the absence of post-translational modifications and disulphide bonds of NanoLuc luciferase enable its rapid synthesis and folding, thus reducing total assay time, moreover the use of its destabilized version provides a half-life of $5 \mathrm{~min}$ in yeast, compared to $40 \mathrm{~min}$ of the yNluc [3223], thus faithfully reflecting mRNA levels. Yeast cells were sequentially transformed with the two plasmids and single colonies screened for their responsiveness with $10 \mathrm{nM} \mathrm{E} 2$. A new BL substrate composition was formulated to optimize BL emission in yeast cells. The NanoGlo® substrate (containing a lysis buffer optimized for mammalian cells) showed suitable for yeast cells [3223]. However, to increase light output, we formulated an alternative substrate by diluting furimazine $(10 \mu \mathrm{M})$ in YPER buffer, a specific yeast-cell lysis reagent used for the extraction of functionally active solubilized proteins from yeast. The use of this formulation (YPER-Nano) provides both an increased BL emission (20\%) and more stable emission kinetics (signal half-life > $\underline{20 \mathrm{~min}}$ ) compared to NanoGlo® substrate or furimazine alone (signal half-life $<2 \mathrm{~min}$ ). (data not shown).

Dose-response curve for E2 $(0.001-100 \mathrm{nM})$ were obtained using liquid cultures of three positive clones in 96-well microplate format and benchtop luminometer. The yeast-estrogen biosensor 
incubated for $1 \mathrm{~h}$ with different concentrations of E2, shows a limit of detection of $0.010 \pm 0.002$ $\mathrm{nM}$ and an EC50 of $0.6 \pm 0.1 \mathrm{nM}$ (Fig.1b). The nanoYES shows a LOQ of $0.020 \pm 0.005 \mathrm{nM} \mathrm{E} 2$ and mean recovery rate of $93 \pm 11 \%$. The nanoYES response to other estrogenic compounds was also evaluated (Fig.1b) and corresponding limit of detection and EC50s are shown in table 1. The developed yeast estrogen bioreporterassay shows comparable results in terms of ranking of estrogenic activity (E2>EE2>DES $>$ E1) and EC50 values, obtained by previous works based on recombinant yeast cells $\underline{\text { [37-38]. }}$

Design and 3D-printing fabrication of the mobile platform based on GoPro Hero camera The mobile platform was designed to create an all-in-one device based on the GoPro Hero5 camera

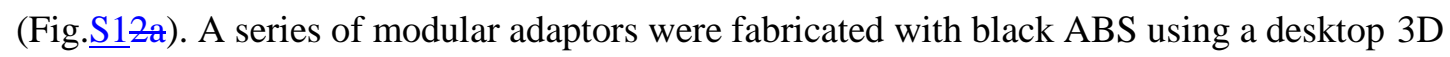
printer, providing a dark box of compact size $(65 \underline{x} 65 \mathrm{~mm}, 60 \mathrm{~mm}$ height $)$ for the acquisition of $\mathrm{BL}$ emission. This accessory also includes a slot to insert a 3D-printed cell-cartridge containing the immobilized nanoYES. The multi-well cartridges $(60 \times \underline{4} 40 \mathrm{~mm})$, containing 16 wells of $5 \times \underline{5} 5 \mathrm{~mm}$ (150 $\mu \mathrm{L}$ volume each), were printed with white and black ABS-(Fig.2b) using the dual extrusion option provided by the Makerbot Replicator 2X. In particular, the bottom of the wells wasere printed using white ABS, while black ABS was used for the remaining parts. This configuration allowed to increase the intensity of acquired BL signal by reflection while avoiding crosstalk between adjacent wells, outperforming cartridges printed with only white or black ABS, that suffered of higher crosstalk and lower signals, respectively.

\section{Immobilization procedure and stability of nanoYES}

To obtain ready-to-use cartridges the nanoYES was immobilized into alginate slices. Cells at OD = 1 (about $1.8 \times{ }_{-} 1^{7}$ cells $/ \mathrm{mL}$ ) were 10 -fold concentrated in culture medium to achieve a sufficient BL 
emission for a sensitive detection with the GoPro camera. The immobilization medium also contains $10 \% \mathrm{w} / \mathrm{v}$ trehalose to increase the shelf life of yeast cells [3928].

A straightforward procedure was developed to generate yeast-alginate slices of defined and reproducible dimension $(2.1 \pm \underline{0} .2 \mathrm{~mm})$ (Fig.S $1 \underline{2})$.

To evaluate the reproducibility of immobilized nanoYES, a whole cell-cartridge (Fig.32a) was incubated with $10 \mathrm{nM}$ E2 for $1 \mathrm{~h}$, and BL image acquired with the GoPro camera (Fig.23b). The quantification of BL emission of 16 slices provided a coefficient of variation $(\mathrm{CV} \%)$ of $11 \%$, which is comparable to previously reported whole-cell bioassays [40] which is acceptable for a whole cell bioassay.

The efficacy of our procedure was compared to conventional method for obtaining alginate beads. A $50 \mu \mathrm{L}$-volume nanoYES/alginate mixture, containing the same cell number for each slice, was added dropwise into a $\mathrm{CaCl}_{2}$ solution and let to harden for $1 \underline{h}_{-}$. Individual beads of about $4.5 \pm \underline{{ }_{-}} 0.3$ mm diameter were obtained, placed into the cell-cartridge wells and treated as for the slices, with 10 $\mathrm{nM}$ E2 for $1 \mathrm{~h}$. The mean BL signal using alginate beads is 8.5 times lower and less reproducible than those obtained with slices, most probably due to a slower and non-uniform distribution of analyte and BL substrate inside the beads (Fig.S $z \underline{3}$ ).

The stability and responsiveness of yeast-estrogen bioreporters immobilized into alginate slices stored at $4_{-}^{\circ} \mathrm{C}$ in the $3 \mathrm{D}$ printed cartridges was evaluated. Each day duplicate wells were incubated with $1 \mathrm{nM}$ E2 for $1 \mathrm{~h}$ and BL images were acquired with the GoPro camera. As shown in Fig.32c, the nanoYES response was consistently maintained within 7 days (85\% of initial response at day 7$)$ and even after two weeks the nanoYES maintains about $70 \%$ of the responsiveness obtained at day 0 (freshly immobilized cells). To guarantee good analytical performance in terms of LOD and sensitivity we decided to use cell-cartridges not older than 10 days, which still provide a BL emission over the $75 \%$ of initial response (arbitrarily selected threshold).

\section{Analytical performance of GoPro-based nanoYES}


The assay in optimized conditions consists of incubation of $50 \mu \mathrm{L}$ of E2 dilutions (concentration range from $0.05-10 \mathrm{nM}$ ) per each cartridge well containing (about $9.0 \underline{x}_{-} 10^{5}$ cells/slice) for $1 \mathrm{~h} \mathrm{at}$ room temperature. Cell cartridge is then imaged with the GoProHero5 camera in night mode for 30

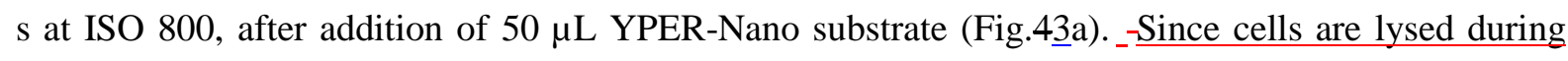
BL emission acquisition, the cartridges are single-use. Fig. $4 \underline{3} \mathrm{~b}$ shows a detailed BL image corresponding to the dose-response curve for E2 acquired 10 min after substrate addition. Doseresponse curves obtained with three different cartridges showed a LOD of $0.08 \pm 0.02 \mathrm{nM}$ and EC50 of $0.7 \pm 0.1 \mathrm{nM} \mathrm{E2} \mathrm{(Fig.4르).} \mathrm{In} \mathrm{the} \mathrm{GoPro-based} \mathrm{platform} \mathrm{the} \mathrm{limit} \mathrm{of} \mathrm{detection} \mathrm{is} \mathrm{about} \mathrm{one}$ order of magnitude higher compared to those obtained with the nanoYES using conventional

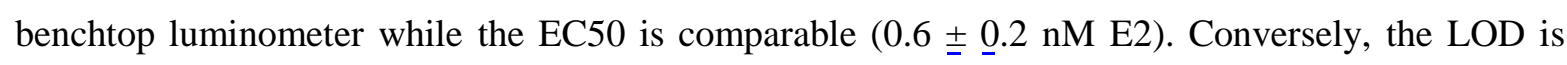
comparable to other previously reported yeast estrogen bioassays, such as those reported by Leskinen et al (0.03 nM for E2) [15]. Also, the EC50 value is consistent with those obtained with similar yeast based screening assays performed in laboratory settings, such as the conventional YES (EC50: $0.32 \mathrm{nM}$ ) [7]. These results confirmed the suitability of this configuration for the straightforward and quantitative detection of estrogenic activity in water samples.

\section{GoPro-based nanoYES: analysis of spiked samples}

As a proof of concept, tap water samples spiked with different concentrations of diethylstilbestrol (DES) and bisphenol A (BPA) were analysed with the GoPro-based nanoYES to explore its actual feasibility for on-site testing, especially for monitoring of sites affected by high pollution such as downstream of industrial manufacturing plants and agricultural areas.

-BPA was selected because of its ability to act as weak ER binder and interfere with the endogenous E2, causing severe effects on the reproductive system [41-42z9-30] while DES is a synthetic nonsteroidal estrogen widely encountered in influents and effluents from municipal water treatment plants with concentrations levels in the range of 4-12 $\mathrm{ng} / \mathrm{L}$ for primary influents [43- 
1

2

3

4

5

6

4431]. BPA is present at relatively high concentrations in several site areas, for example according

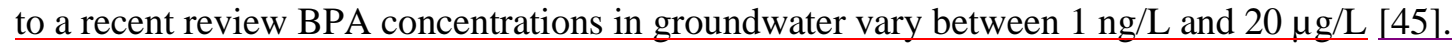
Each disposable cartridge also contains a calibration curve obtained by inducing the nanoYES with 0.5, 1 and $5 \mathrm{nM}$ E2 allowing a rapid evaluation and subsequent interpolation of estrogenic activity of the samples (Fig. $5 \underline{4 a}$ ). Control wells (CTR) were also included and incubated with $1 \%$ EtOH final concentration. Sample-wells were also induced with $0.5 \mathrm{nM} \mathrm{E2}$, a concentration near the EC50, to evaluate both estrogenic and anti- estrogenic activity of samples.

Mean BL emission of each sample was quantified and normalized with respect to $0.5 \mathrm{nM}$ E2, set to 100\% (Fig.54b). Sample no. 1, which contains $10 \mathrm{nM}$ BPA, (simulating a high contaminated sample) shows a remarkable decrease (35\%) of BL emission. indicating the presence of aweak hERa binder. This sample contains $10 \mathrm{nM}$ BPA, simulating a high contaminated sample. At this concentration, BPA (aweak hER $\alpha$ binder) hich binds hER $\alpha$ interfering interferes with the transactivation induced by $0.5 \mathrm{nM} \mathrm{E} 2$, thus decreasing BL emission. Acting as a partial agonist, BPA competes with E2 (full agonist) for receptor occupancy, thus producing a net decrease in the receptor activation compared to that observed with the E2 alone.

Sample no. 2, which contains a very high concentration of a potent estrogen (10 nM DES) and shows a remarkable increase compared to $0.5 \mathrm{nM}$ E2 and,-was selected to simulate the effect based reponsea strong estrogenic effect as in samples containing mixtures of estrogenic compounds $\rightarrow$. Sample no. 3, spiked with $0.1 \mathrm{nM}$ DES (whose concentration does not produce a significantly increased BL signal), and sample no. 4, containing only tap water, did do not show any alteration with respect to $0.5 \mathrm{nM}$ E2, induced transactivation and were spiked with $0.1 \mathrm{nM}$ DES (whose eoncentration is too low does not to produce a significantly increased estrogenic effect) or contains tap water only, respectively.

It must be pointed out that the envisaged application of the platform is for rapid monitoring of effluents of wastewater and critical areas, such as agricultural and industrial sites, in which a high 
concentration of EDCs is expected. Moreover, future studies will be aimed at evaluating the analytical performance of the nanoYES in the presence of EDCs mixtures.

\section{Conclusion}

In this work, we proposed a mobile platform for effect-based analysis of endocrine disruptors, based on bioluminescent yeast estrogen biosensors and a compact wireless camera as light detector.

The newly developed yeast estrogen biosensors exploit a yeast codon optimized variant of Nanoluc luciferase to achieve rapid and sensitive detection of estrogen-like compounds within $1 \mathrm{~h}$. A straightforward procedure to immobilize the yeast biosensors into 3D printed cartridges was also developed, obtaining reproducible ready-_to-_use disposable cartridges that can stored for 10 days at 4 ${ }_{-}^{\circ} \mathrm{C}$ without significant decrease in analytical performance.

The GoPro camera proved suitable for the sensitive detection of light emission from bioluminescent yeast biosensors, using the night mode setup with $30 \mathrm{~s}$ integration time. In addition, thanks to the possibility to connect this sensor with any smartphone model via dedicated GoProApp, the developed configuration results in a more standardized and versatile platform, compared to smartphone-based devices. A custom application (APP) running on different operative systems could be developed to either provide instructions to the user and for the quantification of BL images to obtain immediate results about estrogenic activity of samples.

In the proposed configuration, the mobile platform, containing robust microbial bioluminescent whole-cell bioreporters, allows a rapid evaluation of estrogenic activity in water samples and could find application for on-site analysis of EDCs.

\section{Notes}

The authors declare no competing financial interest.

\section{Acknowledgments}




\section{Page 17 of 34}

1

2

3

4

5

$\frac{6}{7}$

7

8

9

10

11

12

13

14

15

16

17

18

19

20

21

22

23

24

25

26

27

28

29

30

31

32

33

34

35

36

37

38

39

40

41

42

43

44

45

46

47

48

49

50

51

52

53

54

55

56

57

58

59

60
This research was sponsored in part by PRIN 2015 "Securing and ensuring sustainable use of agriculture waste, co- and by-products: an integrated analytical approach combining mass spectrometry with health effect-based biosensing" (Prot. 2015FFY97L) and the NATO Science for Peace and Security Programme under Grant No.985042. 


\section{References}

1. http://eur-lex.europa.eu/legal-content/EN/TXT/HTML/?uri=CELEX:32013L0039\&from=IT (last accessed 26 July 2017)

2. Watson R. European Commission tables scientific criteria for endocrine disruptors. BMJ. 2016;353:i3459

3. Kunz PY, Simon E, Creusot N, Jayasinghe BS, Kienle C, Maletz S, Schifferli A, Schönlau C, Aït-Aïssa S, Denslow ND, Hollert H, Werner I, Vermeirssen EL. Effect-based tools for monitoring estrogenic mixtures: Evaluation of five in vitro bioassays. Water Res. 2017; 110:378-88.

4. Ewence A, Brescia S, Johnson I, Rumsby PC. An approach to the identification and regulation of endocrine disrupting pesticides. Food Chem Toxicol. 2015;78:214-20.

5. Barbosa MO, Moreira NF, Riberio AR, Pereira MF, Silva AM. Occurrence and removal of organic micropollutants: an overview of the watch list of EU Decision 2015/495. Water Res. 2016;94:257-79.

6. Tiedeken EJ, Tahar A, McHugh B, Rowan NJ. Monitoring, sources, receptors, and control measures for three European Union watch list substances of emerging concern in receiving waters - A 20year systematic review. Sci Total Environ. 2017;574:1140-63.

7. Escher BI, Neale PA, Leusch FD. Effect-based trigger values for in vitro bioassays: Reading across from existing water quality guideline values. Water Res. 2015;81:137-48.

8. Mertl J, Kirchnawy C, Osorio V, Grininger A, Richter A, Bergmair J, Pyerin M, Washüttl M, Tacker M. Characterization of estrogen and androgen activity of food contact materials by different in vitro bioassays (YES, YAS, ER $\alpha$ and AR CALUX) and chromatographic analysis (GC-MS, HPLC-MS). PLoS One. 2014;9:e100952.

9. Gauglitz G. ABC Spotlight on effect-directed analysis--dose instead of concentration. Anal Bioanal Chem. 2015;407:3261-3. 
10. Fang TY, Praveena SM, deBurbure C, Aris AZ, Ismail SN, Rasdi I. Analytical techniques for steroid estrogens in water samples - A review. Chemo. 2016;165:358-68.

11. Roda A, Mirasoli M, Michelini E, Magliulo M, Simoni P, Guardigli M, Curini R, Sergi M, Marino A. Analytical approach for monitoring endocrine-disrupting compounds in urban waste water treatment plants. Anal Bioanal Chem. 2006;385:742-52.

12. Comtois-Marotte S, Chappuis T, Vo Duy S, Gilbert N, Lajeunesse A, Taktek S, Desrosiers M, Veilleux É, Sauvé S. Analysis of emerging contaminants in water and solid samples using high resolution mass spectrometry with a Q Exactive orbital ion trap and estrogenic activity with YES-assay. Chemosphere. 2017;166:400-11.

13. Wang S, Bovee TFH. Estrogen Receptor Agonists and Antagonists in the Yeast Estrogen Bioassay. Methods Mol Biol. 2016;1366:337-42.

14. Bovee TF, Heskamp HH, Hamers AR, Hoogenboom RL, Nielen MW. Validation of a rapid yeast estrogen bioassay, based on the expression of green fluorescent protein, for the screening of estrogenic activity in calf urine. Analytica chim acta. 2005;529:57-64.

15. Leskinen P, Michelini E, Picard D, Karp M, Virta M. Bioluminescent yeast assays for detecting estrogenic and androgenic activity in different matrices. Chemosphere. $2005 ; 61: 259-66$.

16. Chu WL, Shiizaki K, Kawanishi M, Kondo M, Yagi T. Validation of a new yeast-based reporter assay consisting of human estrogen receptors alpha/beta and coactivator SRC-1: application for detection of estrogenic activity in environmental samples. Environ Toxicol. 2009 Өet;24(5):513-21.

17. Escande A, Pillon A, Servant N, Cravedi JP, Larrea F, Muhn P, Nicolas JC, Cavaillès V, Balaguer P. Evaluation of ligand selectivity using reporter cell lines stably expressing estrogen receptor alpha or beta. Biochem Pharmacol. 2006 May 14;71(10):1459-69. 
18. Gutendorf B, Westendorf J. Comparison of an array of in vitro assays for the assessment of the estrogenic potential of natural and synthetic estrogens, phytoestrogens and xenoestrogens. Toxicology. 2001;166:79-89.

19. Gaido KW, Leonard LS, Lovell S, Gould JC, Babaï D, Portier CJ, McDonnell DP. Evaluation of chemicals with endocrine modulating activity in a yeast-based steroid hormone receptor gene transcription assay. Toxicol Appl Pharmacol. 1997;143:205-12.

20. Klein KO, Baron J, Colli MJ, McDonnell DP, Cutler GB Jr. Estrogen levels in childhood determined by an ultrasensitive recombinant cell bioassay. J Clin Invest. 1994;94:2475-80.

21. Leusch FD, de Jager C, Levi Y, Lim R, Puijker L, Sacher F, Tremblay LA, Wilson VS, Chapman HF. Comparison of five in vitro bioassays to measure estrogenic activity in environmental waters. Environ Sci Technol. 2010;44:3853-60.

22. Coldham NG, Dave M, Sivapathasundaram S, McDonnell DP, Connor C, Sauer MJ. Evaluation of a recombinant yeast cell estrogen screening assay. Environ Health Perspect. 1997;105:734-42.

23. Furst AL, Hoepker AC, Francis MB. Quantifying Hormone Disruptors with an Engineered Bacterial Biosensor. ACS Cent Sci. 2017;3:110-6.

Liu L, Zhou X, Lu Y, Shan D, Xu B, He M, Shi H, Qian Y. Facile screening of potential $\underline{\text { xenoestrogens by an estrogen receptor-based reusable optical biosensor. Biosens }}$

Bioelectron. 2017;97:16-20.

15.24 .

16.25. Sonneveld E, Jansen HJ, Riteco JA, Brouwer A, van der Burg B. Development of androgen- and estrogen-responsive bioassays, members of a panel of human cell line-based highly selective steroid-responsive bioassays. Toxicol Sci. 2005;83:136-48.

17.26. Soto AM, Sonnenschein C, Chung KL, Fernandez MF, Olea N, Serrano FO. The ESCREEN assay as a tool to identify estrogens: an update on estrogenic environmental pollutants. Environ Health Perspect. 1995;103:113-22. 
18.27. Routledge EJ, Sumpter JP. Estrogenic activity of surfactants and some of their degradation products assessed using a recombinant yeast screen. Environ Toxicol. Chem. 1996;15: 241-8.

19.28. Roda A, Cevenini L, Michelini E, Branchini BR. A portable bioluminescence engineered cell-based biosensor for on-site applications. Biosens Bioelectron. 2011;26:3647-53.

20.29. Cevenini L, Calabretta MM, Lopreside A, Tarantino G, Tassoni A, Ferri M, Roda A, Michelini E. Exploiting NanoLuc luciferase for smartphone-based bioluminescence cell biosensor for (anti)-inflammatory activity and toxicity. Anal Bioanal Chem. 2016;408:885968

21.30. Cevenini L, Calabretta MM, Tarantino G, Michelini E, Roda A. Smartphoneinterfaced 3D printed toxicity biosensor integrating bioluminescent "sentinel cells". Sens Act B Chem. 2016;225:249-57

22.31. Hall MP, Unch J, Binkowski BF, Valley MP, Butler BL, Wood MG, Otto P, Zimmerman K, Vidugiris G, Machleidt T, Robers MB, Benink HA, Eggers CT, Slater MR, Meisenheimer PL, Klaubert DH, Fan F, Encell LP, Wood KV. Engineered luciferase reporter from a deep sea shrimp utilizing a novel imidazopyrazinone substrate. ACS Chem Biol. 2012;7:1848-57.

23.32. Masser AE, Kandasamy G, Kaimal JM, Andréasson C. Luciferase NanoLuc as a reporter for gene expression and protein levels in Saccharomyces cerevisiae. Yeast. 2016;33:191-200.

24.33. Mattingly KA, Ivanova MM, Riggs KA, Wickramasinghe NS, Barch MJ, Klinge CM. Estradiol stimulates transcription of nuclear respiratory factor-1 and increases mitochondrial biogenesis. Mol Endocrinol. 2008;22:609-22 
25.34. Baudin-Bailleu A, Guillemet E, Cullin C, Lacroute F. Construction of a yeast strain deleted for the TRP1 promoter and coding region that enhances the efficiency of the polymerase chain reaction disruption method. Yeast 1996;30:353-6.

26.35. Sambrook EF, Fristch, EF, Maniatis T, Molecular Cloning: A Laboratory Manual, 2nd ed. Cold Spring Harbor Laboratory Press, New York 1989.

36. Jarque S, Bittner M, Blaha L, Hilscherova K. Yeast Biosensors for Detection of Environmental Pollutants: Current State and Limitations. Trends Biotechnol. 2016;34:40819.

\section{Céspedes R, Petrovic M, Raldúa D, Saura U, Piña B, Lacorte S, Viana P, Barceló D.} Integrated procedure for determination of endocrine-disrupting activity in surface waters and $\underline{\text { sediments by use of the biological technique recombinant yeast assay and chemical analysis }}$ by LC-ESI-MS. Anal Bioanal Chem. 2004;378:697-708.

38. Bergamasco AM, Eldridge M, Sanseverino J, Sodré FF, Montagner CC, Pescara IC, Jardim WF, Umbuzeiro Gde A. Bioluminescent yeast estrogen assay (BLYES) as a sensitive tool to monitor surface and drinking water for estrogenicity. J Environ Monit. 2011 Nor; $13(11): 3288-93$

39. Kim DH, Lee SB, Park HD. Effect of air-blast drying and the presence of protectants on the viability of yeast entrapped in calcium alginate beads with an aim to improve the survival rate. Appl Microbiol Biotechnol. 2017;101:93-102.

Balsiger HA, de la Torre R, Lee WY, Cox MB. A Four-Hour Yeast Bioassay for the Direct Measure of Estrogenic Activity in Wastewater without Sample Extraction, Concentration, or Sterilization. Sci Total Environ. 2010; 408:1422-9.

27.40 . 
28.41. Cao H, Wang F, Liang Y, Wang H, Zhang A, Song M. Experimental and computational insights on the recognition mechanism between the estrogen receptor $\alpha$ with bisphenol compounds. Arch Toxicol. 2017;91:1-16.

29.42. FitzGerald RE, Wilks MF. Bisphenol A-Why an adverse outcome pathway framework needs to be applied. Toxicol Lett. 2014;230:368-74

43. Frye CA, Bo E, Calamandrei G, Calzà L, Dessì-Fulgheri F, Fernández M, Fusani L, Kah O, Kajta M, Le Page Y, Patisaul HB, Venerosi A, Wojtowicz AK, Panzica GC. Endocrine disrupters: a review of some sources, effects, and mechanisms of actions on behaviour and neuroendocrine systems. J Neuroendocrinol. 2012;24:144-59.

44. Jin S, Yang F, Liao T, Hui Y, Xu Y. Seasonal variations of estrogenic compounds and their estrogenicities in influent and effluent from a municipal sewage treatment plant in China.

Environ Toxicol Chem. 2008Jan;27(1):146-53. Seasenal compounds and their estrogenicities in influent and effluent from a municipal sewage treatment plant in China. Jin S1, Yang F, Liao T, Hui Y, Xu Y

\subsection{5. (Alessande Careghini A, Andrea Filippe Mastorgio AF, Sabrina Saponaro}

$\underline{\text { S,corresponding author and Elena Sezenna E. Bisphenol A, nonylphenols, benzophenones, }}$ and benzotriazoles in soils, groundwater, surface water, sediments, and food: a review. Environ Sci Pollut Res Int. 2015; 22(8): 5711-5741. Bisphenol A, nonylphenols, benzophenones, and benzotriazoles in soils, groundwater, surface water, sediments, and food: a review). 


\title{
Figure legends
}

Fig. 1 a) Schematic representation of the bioluminescent yeast-estrogen strain. S. cerevisiae cells were transformed with a plasmid for the expression of the human estrogen receptor $\alpha(\mathrm{hER} \alpha)$ under the control of the weak constitutive ADH1 promoter. Cells were also transformed with a vector containing five copies of estrogen response element (ERE) and the cDNA encoding for the yeast codon optimized NanoLuc luciferase destabilized variant (yNLucP). Both vectors contain a $2 \mu$ replication origin for their propagation during yeast growth. The binding of estrogens such as $17 \beta-$ estradiol (E2) to hER $\alpha$ activates the intracellular signalling pathway (receptor dimerization) which leads to the expression of yNLucP luciferase. Light emission is obtained after addition of an optimized substrate solution containing furimazine (2-furanylmethyl-deoxy-coelenterazine). b) Dose-response curves for different estrogenic compounds (E2: 17 $\beta$-estradiol; EE2: $17 \alpha$ ethynylestradiol; DES: diethylstilbestrol; E1: estrone) obtained using the nanoYES performed in 96- well microplate format and benchtop instrumentation. Data represent the mean values \pm the standard deviation (SD) obtained with three replicates and repeating the experiments three times.

\author{
Fig. 2S1 a) 3D printed accessory designed to hold a GoPro Hero5 creating a self-supporting device. \\ The alaptor $(65 \times 65 \mathrm{~mm}, 60 \mathrm{~mm}$ height $)$ provides a dark box for acquisition of biolmminescent \\ emission and integrates a slot to house the cell-cartridge. b) Multi-well cartridge $(60 \times 40 \mathrm{~mm})$ \\ printed with white and black ABS containing 16 wells of $5 \times 5 \mathrm{~mm}$ (150 $\mu \mathrm{L}$ volume each) to house \\ the cell-alginate slices.
}

Fig. 32 a) Picture of a 3D printed cartridge containing 16 alginate slices of yeast-estrogen bioreporters. b) BL image of 16 yeast-estrogen biosensors slices induced with $10 \mathrm{nM}$ E2, acquired

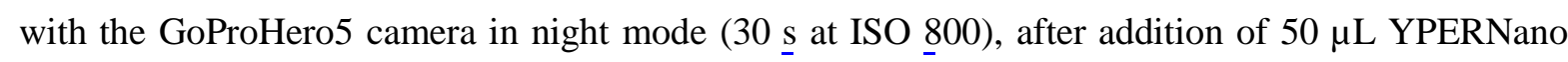
solution. c) Responsiveness of immobilized yeast-bioreporters stored at $4{ }^{\circ} \mathrm{C}$. Each day duplicate 
wells were treated with $1 \mathrm{nM}$ E2 and BL emissions were acquired with the GoPro camera. BL signals are normalized with respect to day $\underline{0}$ (freshly immobilized cells).

Fig. $\mathbf{3} 4$ a) Picture of a typical yeast estrogen assay performed by incubating the cell-cartridge containing immobilized yeast bioreporters with $50 \mu \mathrm{L}$ of sample and by acquiring BL emission with a GoProHero5 camera in night mode (30 s at ISO 800), after addition of $50 \mu \mathrm{L}$ YPERNano solution. b) BL image obtained by incubating the yeast-bioreporters with $17 \beta$-estradiol (concentration range from $0.05 \mathrm{nM}$ to $10 \mathrm{nM}$ ) and c) corresponding dose-response curve for $17 \beta$ estradiol obtained after quantification of BL emission with ImageJ software. Data are plotted as fold response with respect to control (1\% EtOH).

Fig. 54 a) BL Image of a proof-of-concept analysis of spiked water samples and b) Quantitative elaboration where BL emissions were normalized with respect to $0.5 \mathrm{nM}$ E2 set at 100 . graphical elaboration of a proof-of-concept analysis of real samples. The configuration of the cell-cartridge allows to test the estrogenic activity of four samples in duplicate. The response of nanoYES to 0.5, 1, and $5 \mathrm{nM}$ E2 was also included in each cartridge, allowing a quick evaluation and quantification of estrogenic activity. Sample wells are co-incubated with $0.5 \mathrm{nM}$ E2 to detect both pro- and antiestrogenic activity. As a proof-of-concept, three tap water samples were analyzed: sample no. 1 (S1) was spiked with $10 \mathrm{nM}$ bisphenol A (BPA) shows anti-estrogenic activity. BPA (which does not produce a detectable BL signal at this concentration) is able to bind to the estrogen receptor thus interfering with the transactivation induced by $0.5 \mathrm{nM}$ E2. Sample no. 2 (S2) which contains $10 \mathrm{nM}$ diethylstylbestrol (DES) shows a remarkable increase compared to $0.5 \mathrm{nM}$ E2 (comparable to BL signal obtained in the presence of $5 \mathrm{nM}$ E2). Sample no. 3 (S3) was spiked with $0.1 \mathrm{nM}$ diethylstylbestrol (DES), this concentration does not produce any estrogenic effect. Sample no. 4 (S4) contains only $50 \mu \mathrm{L}$ tap water and has no estrogenic effect. All measurements were performed in duplicate and repeated with three different cell cartridges. 
Table 1. nanoYES response to estrogenic compounds, obtained using liquid cultures, in 96 well plate format and benchtop luminometer.

\begin{tabular}{|l|c|c|}
\hline Compound & LOD (nM) & EC50 (nM) \\
\hline 17ß-estradiol (E2) & $0.010 \pm 0.002$ & $0.6 \pm 0.1$ \\
\hline $\mathbf{1 7} \boldsymbol{\alpha}$-ethynylestradiol (EE2) & $0.05 \pm 0.01$ & $1.2 \pm 0.3$ \\
\hline Diethylstilbestrol (DES) & $0.019 \pm 0.005$ & $5.2 \pm 0.5$ \\
\hline Estrone (E1) & $0.5 \pm 0.1$ & $17 \pm 2$ \\
\hline
\end{tabular}




\section{Page 27 of 34}

1
2
3
4
5
6
7
8
9
10
11
12
13
14
15
16
17
18
19
20
21
22
23
24
25
26
27
28
29
30
31
32
33
34
35
36
37
38
39
40
41
42
43
44
45
46
47
48
49
50
51
52
53
54
55
56
57
58
60

a

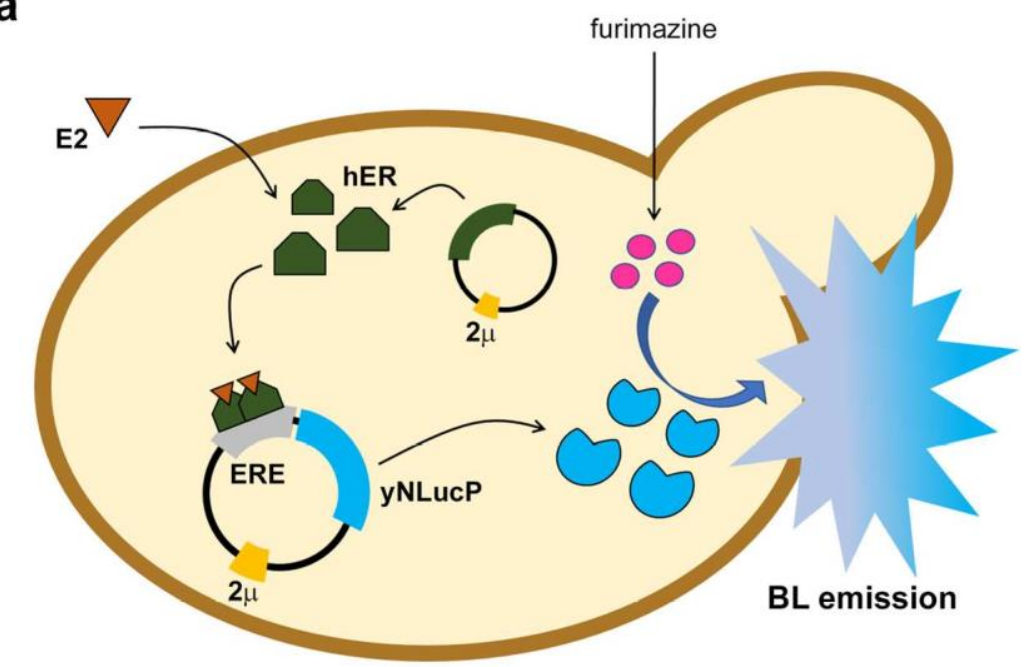

b

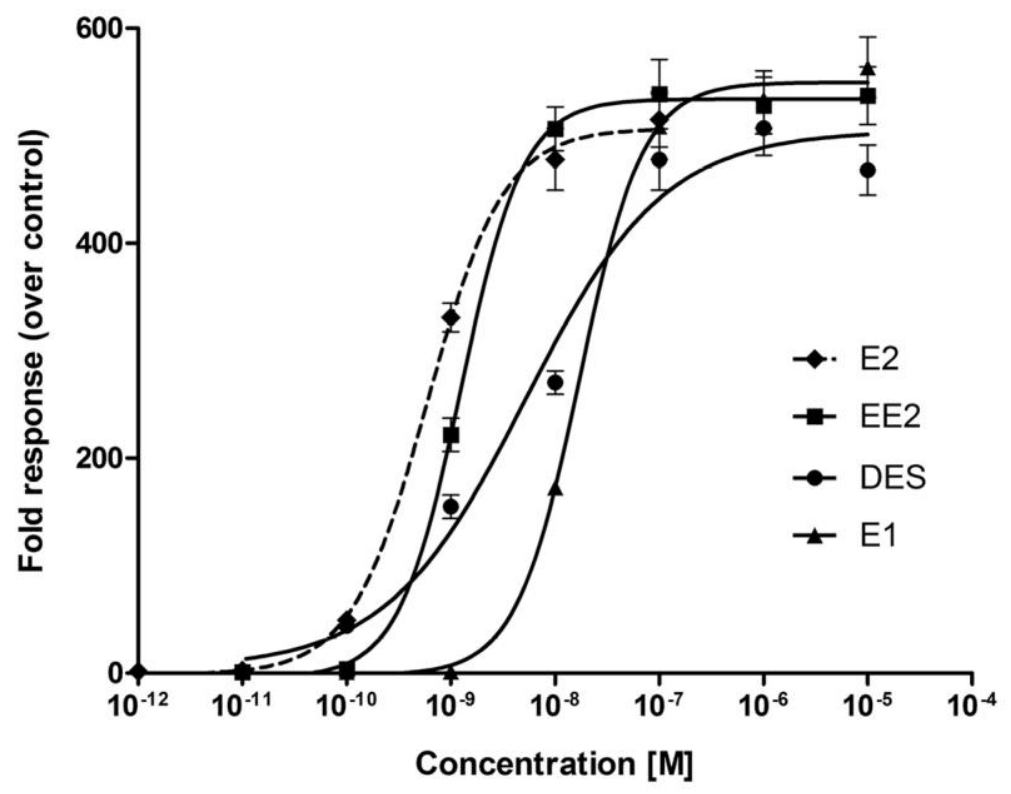

$119 \times 173 \mathrm{~mm}(300 \times 300$ DPI) 
a

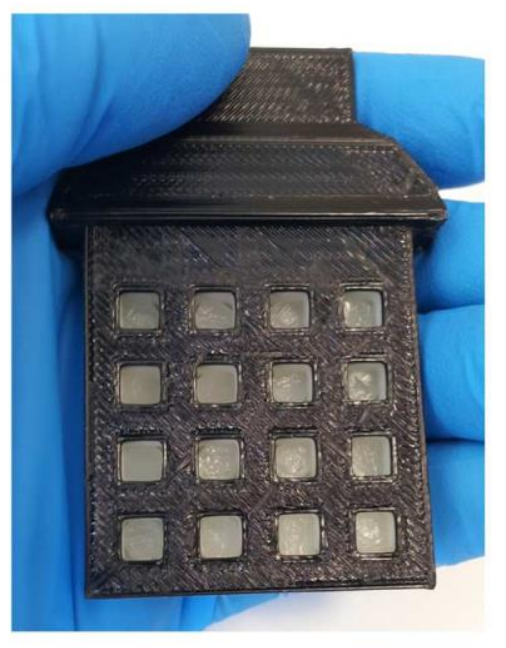

b

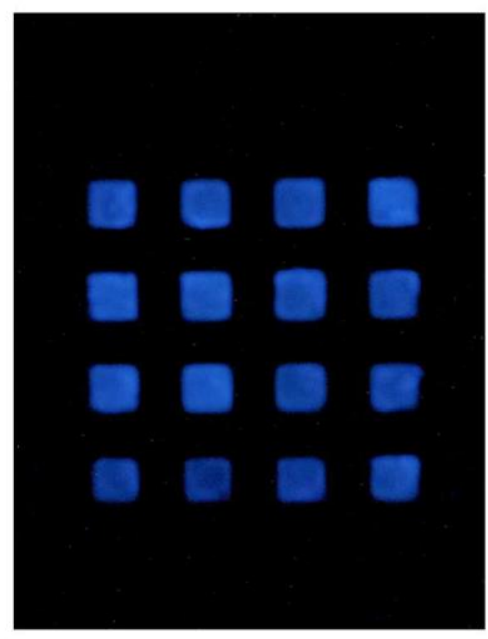

C

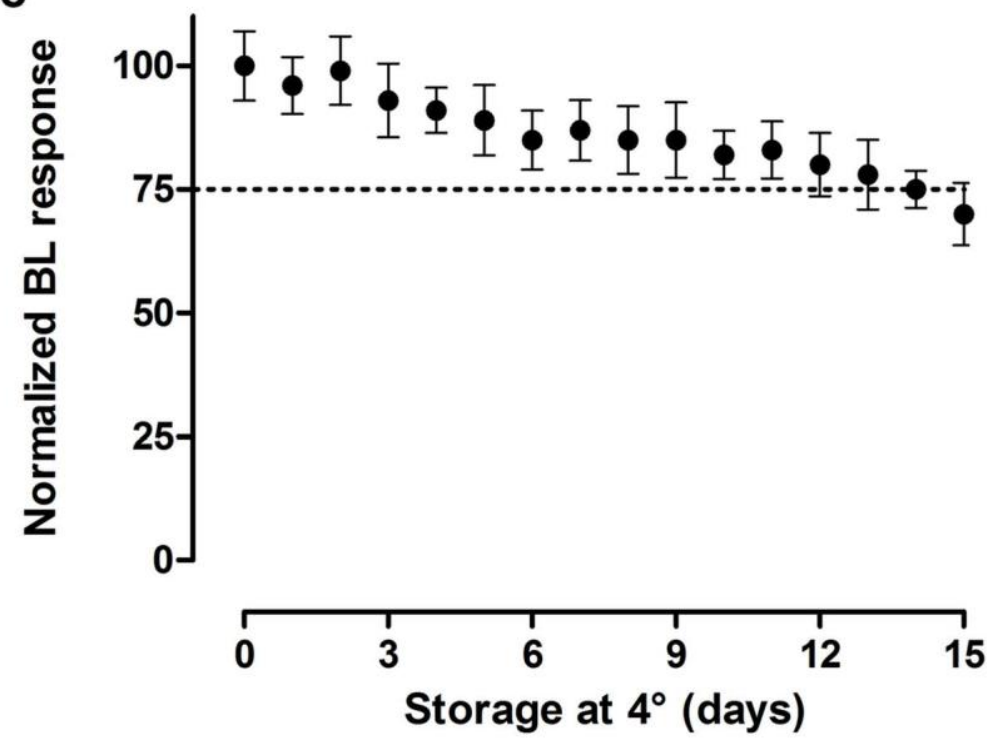

$109 \times 151 \mathrm{~mm}(300 \times 300$ DPI $)$ 


\section{Page 29 of 34}

a

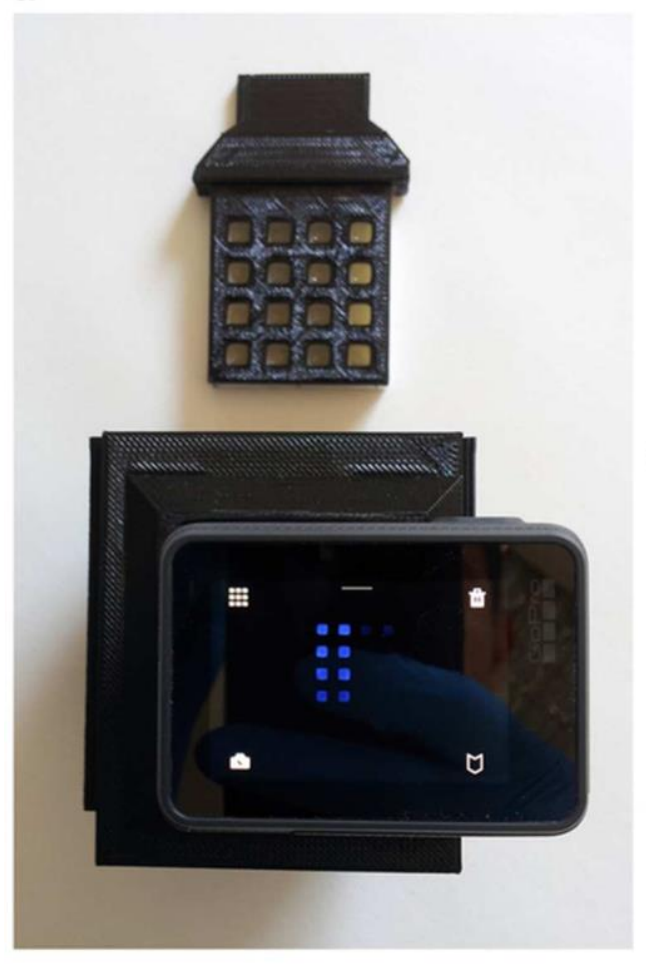

b

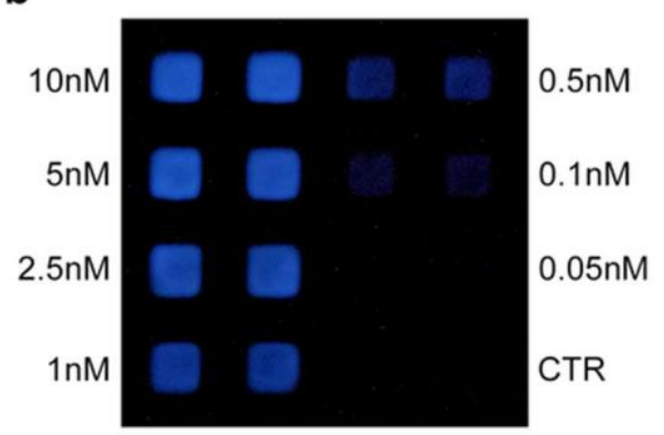

C

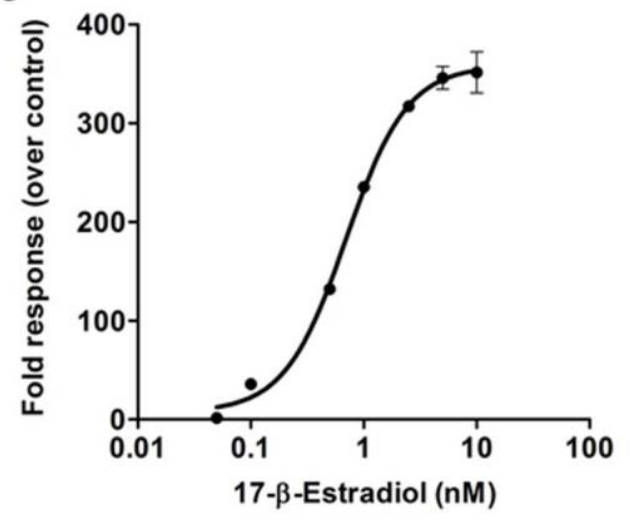

$64 \times 50 \mathrm{~mm}(300 \times 300 \mathrm{DPI})$

36

37

38

39

40

41

42

43

44

45

46

47

48

49

50

51

52

53

54

55

56

57

58

59

60 
a

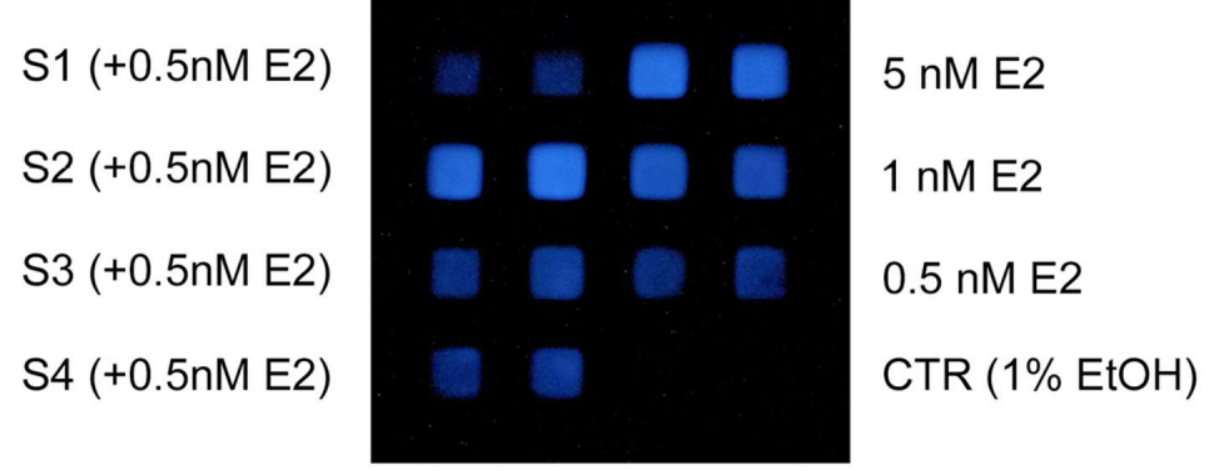

b

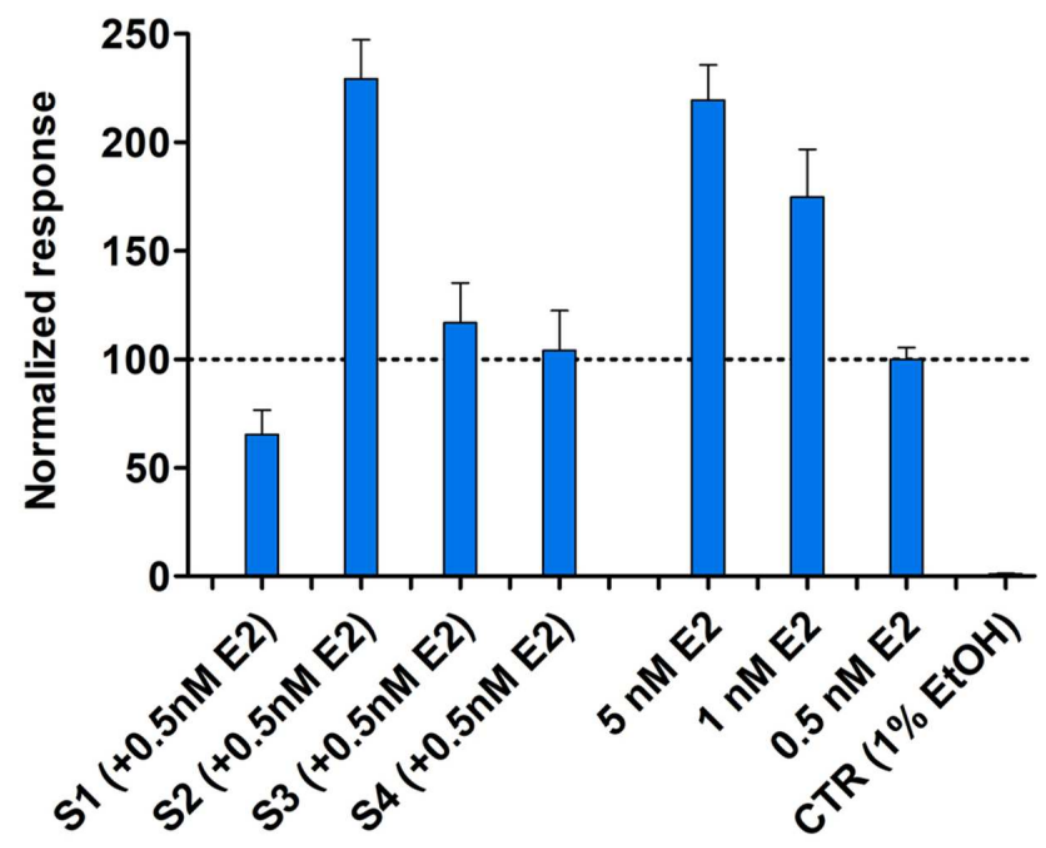

$99 \times 120 \mathrm{~mm}(300 \times 300 \mathrm{DPI})$ 


\section{Page 31 of 34}

1
2
3
4
5
6
7
8
9
10
11
12
13
14
15
16
17
18
19
20
21
22
23
24
25
26
27
28
29
30
31
32
33
34
35
36
37
38
39
40
41
42
43
59
60
45
46
47
48
49
50
51
52
53
55

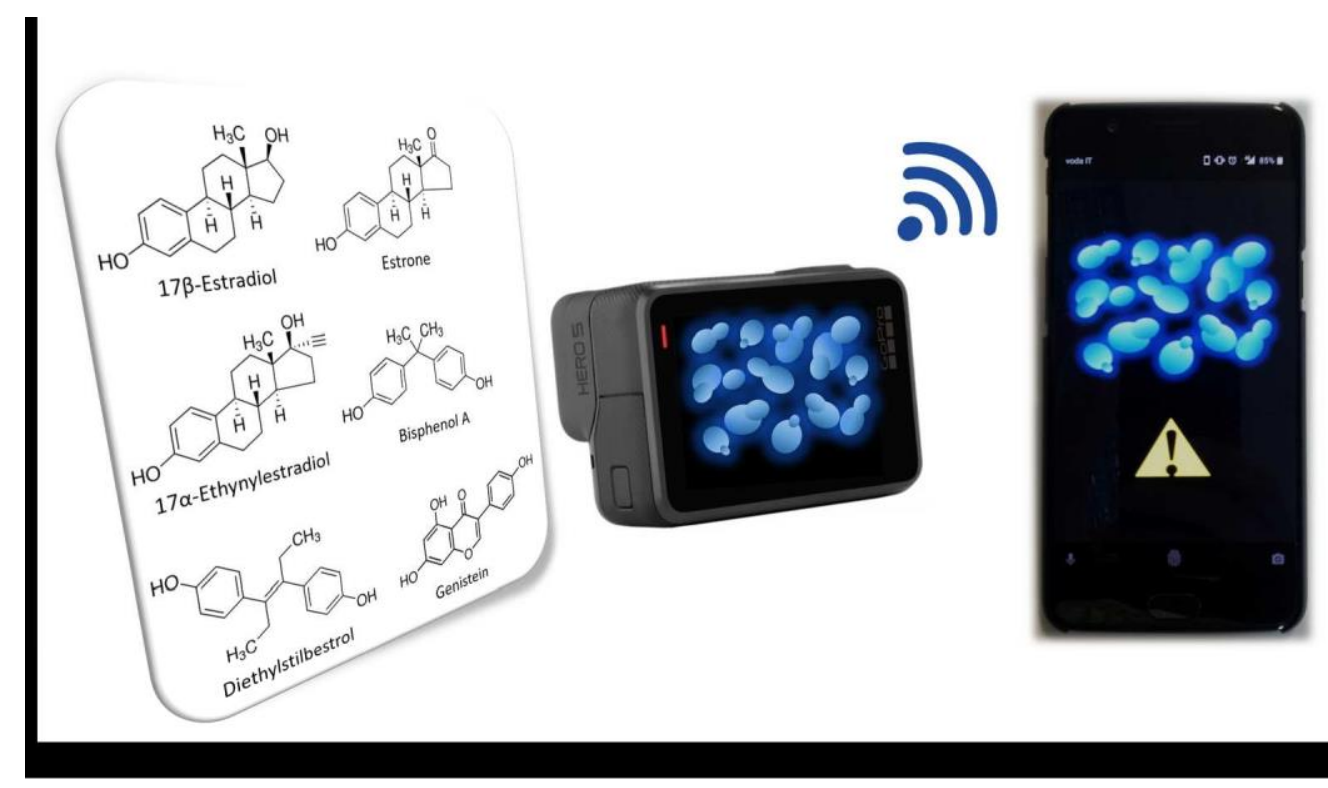

$533 \times 312 \mathrm{~mm}(96 \times 96 \mathrm{DPI})$ 


\section{Supplementary material}

\section{A novel bioluminescent NanoLuc yeast-estrogen screen biosensor (nanoYES) with a compact wireless camera for effect-based detection of endocrine disrupting chemicals}

Cevenini Luca ${ }^{1}$, Lopreside Antonia ${ }^{1}$, Calabretta Maria Maddalena ${ }^{1}, D^{\prime}$ Elia Marcello $^{2}$, Simoni Patrizia ${ }^{3}$, Michelini Elisa ${ }^{* 1,4,5}$, Roda Aldo ${ }^{1,4}$

a

a

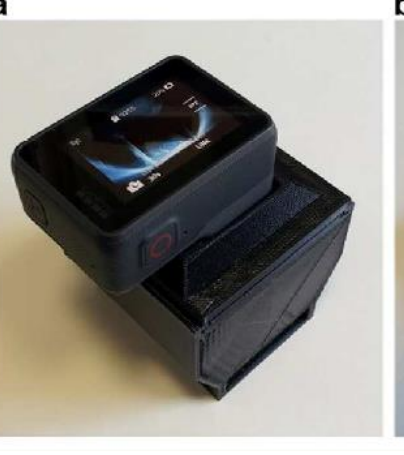

b

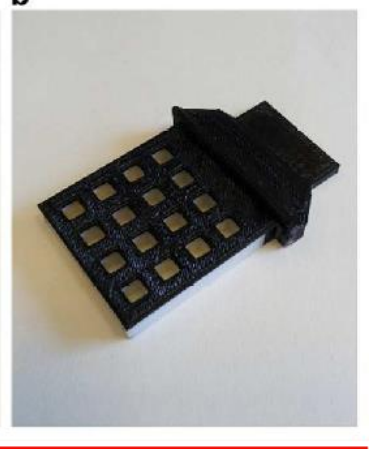

Fig. S1 a) 3D printed accessory designed to hold a GoPro Hero5 creating a self-supporting device. The adaptor $(65 \times 65 \mathrm{~mm}, 60 \mathrm{~mm}$ height $)$ provides a dark box for acquisition of bioluminescent emission and integrates a slot to house the cell-cartridge. b) Multi-well cartridge $(60 \times 40 \mathrm{~mm})$ printed with white and black ABS containing 16 wells of $5 \times 5 \mathrm{~mm}(150 \mu \mathrm{L}$ volume each) to house the cell-alginate slices. 


\section{a}

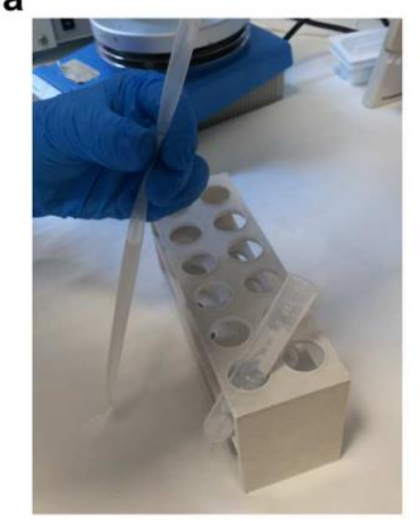

d

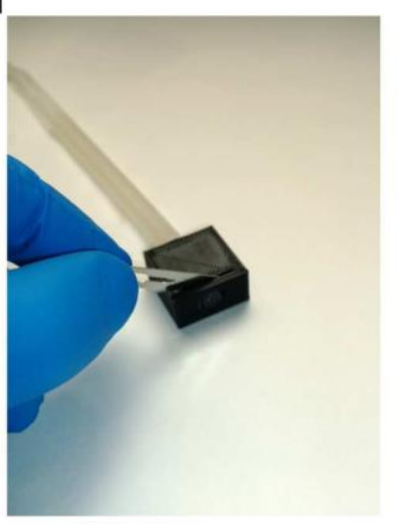

b
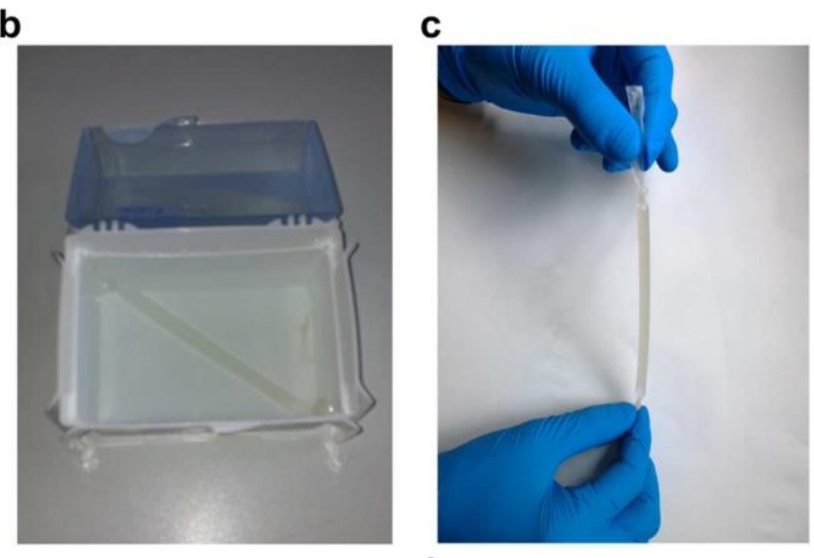

e
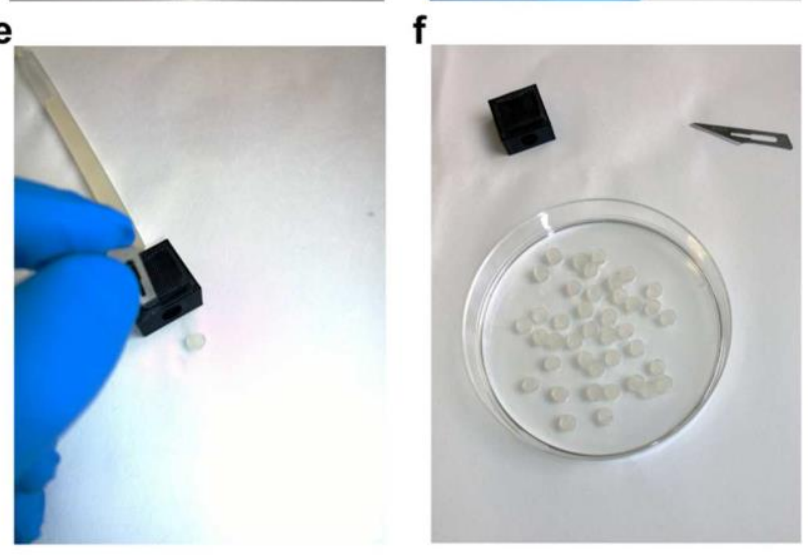

Fig. S12 Immobilization of nanoYES in alginate slices. a) Yeast cultures at $\mathrm{OD}_{600}=1$ (about $1.8 \times 10^{7}$ cells $/ \mathrm{mL})$ were concentrated $10 \mathrm{X}$ in culture medium containing trehalose $(10 \% \mathrm{w} / \mathrm{v})$ and poured $(3$ $\mathrm{mL}$ of yeast culture) into a dialysis tubing cellulose membrane (avg. flat width $10 \mathrm{~mm}$, molecular weight cut-off $=14 \mathrm{KDa}$ ). b) The membrane was then immersed into a $\mathrm{CaCl}_{2}$ solution to allow the formation of the gel inside the membrane. c) After $1 \mathrm{~h}$ incubation at room temperature $\left(25^{\circ} \mathrm{C}\right)$ the yeast-bioreporter are immobilized into calcium alginate matrix and ready for the next steps. d) The obtained gel (about $12 \mathrm{~cm}$ length, avg. diameter 5mm) is inserted in a 3D printed "microtome-like" device fabricated for the straightforward production of slices with defined dimension. e) The microtome has a slot for a surgical blade placed at $2 \mathrm{~mm}$ from the edge, allowing to repeatedly cut the gel by simply realigning it to the edge after each slice. f) Using this technique about 48 slices of 2.1 $\pm 0.2 \mathrm{~mm}$ were obtained, which are sufficient for the production of three cartridges. 


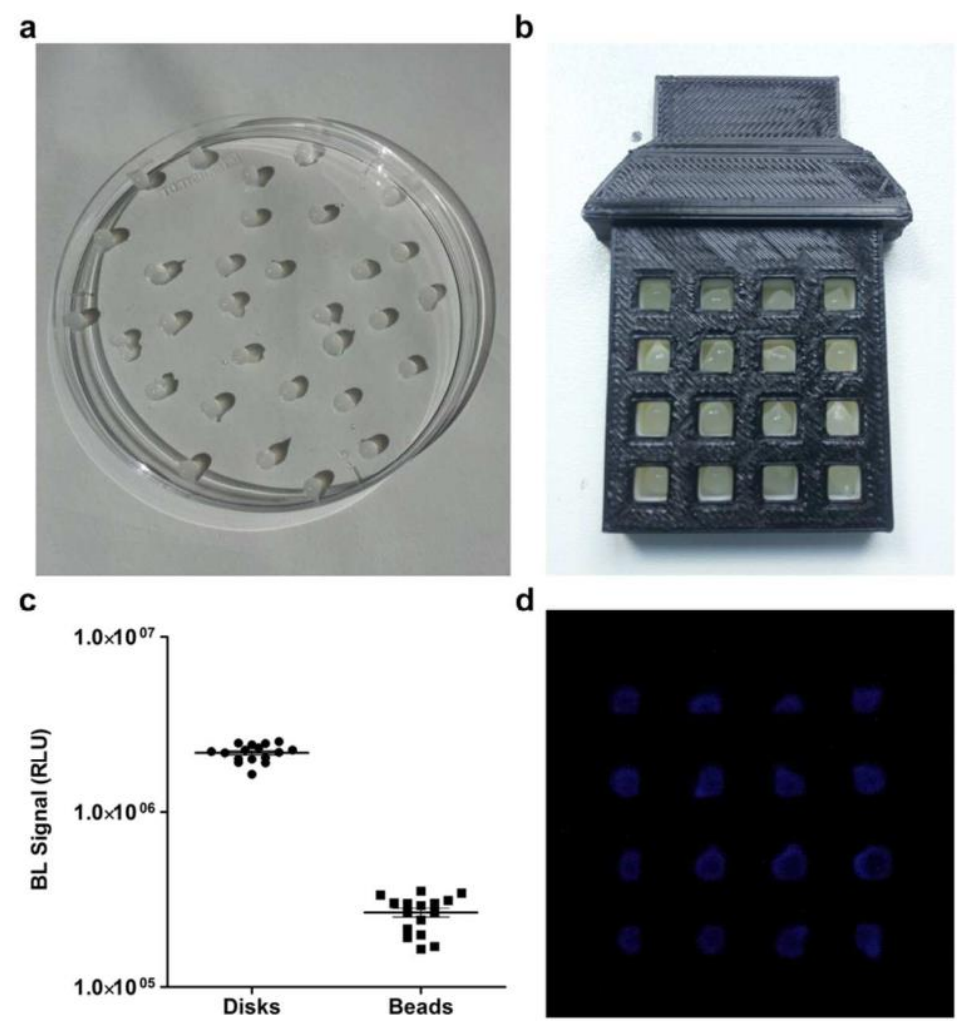

Fig. S2z $\underline{3}$ Comparison with yeast immobilized in alginate beads. a) Picture of alginate beads obtained with the conventional procedure by dripping $50 \mu \mathrm{L}$ of nanoYES-alginate mixture into a $0.1 \mathrm{M} \mathrm{CaCl}_{2}$ agitated solution. b) Picture of the alginate beads (avg. diameter $4.5 \mathrm{~mm}$ ) into a 3D printed cartridge. c) BL emission intensities and distribution of nanoYES immobilized in alginate slices or beads and induced with $10 \mathrm{nM}$ E2. d) BL image of nanoYES immobilized in alginate beads and induced with $10 \mathrm{nM}$ E2. 